\title{
FORMULATION AND EVALUATION OF EXTENDED RELEASE PELLETS OF PIOGLITAZONE HYDROCHLORIDE USING NATURAL AND SYNTHETIC POLYMERS BY FLUIDIZED BED COATING TECHNIQUE
}

\author{
GOWTHAMI B, NIHITHA S, SANTHI PRIYA NAGAM*, RAMA RAO NADENDLA
}

Department of Pharmaceutics, Chalapathi Institute of Pharmaceutical Sciences, Guntur, Andhra Pradesh. Email: santhipriyampharm@gmail.com Received: 21 November 2018, Revised and Accepted: 28 December 2018

\section{ABSTRACT}

Objective: The objective of the current work was to develop Pioglitazone hydrochloride ( $\mathrm{HCl}$ ) pellets coated with natural polymer extracted from peas gum and also to compare the drug release profile with coatings containing semi-synthetic and synthetic polymers.

Methods: Fluidized bed coating technique was used to develop pellets. A $2^{2}$ factorial design was employed to study the effect of independent variables (inlet air temperature and spray rate), on dependent variables (percentage entrapment efficiency, percentage friability, and average particle size). Optimization was done by fitting experimental data to the software program. Obtained pellets were subjected to different evaluation parameters which are critical in the development of the dosage form. An in vitro lag phase study was carried out for all batches in simulated gastric fluid $(0.1 \mathrm{~N} \mathrm{HCl})$ for $5 \mathrm{~h}$ and in vitro drug release study was carried out for optimized batch (E-2 and P-3) in simulated intestinal fluid (pH 7.4 phosphate buffer).

Results: The optimized batches E- 2 and P-3 showed satisfactory percentage entrapment efficiency of $92.66 \pm 1.52$, percentage friability of $0.57 \pm 0.03$, and average particle size of $1424 \pm 16 \mu \mathrm{m}$. All batches maintained lag phase for $5 \mathrm{~h} \mathrm{in} 0.1 \mathrm{~N} \mathrm{HCl}$. An optimized batch of two different sizes exhibited a burst release within $30 \mathrm{~min}$ in a simulated intestinal fluid with no significant difference in release rate constant $\left({ }^{*} \mathrm{p}>0.05\right)$ and followed first-order kinetics.

Conclusion: Thus, Pioglitazone $\mathrm{HCl}$ pulsatile pellets were successfully developed for treating diabetes mellitus by fluidized bed coating technique employing factorial design.

Keywords: Pioglitazone hydrochloride, Peas gum, Eudragit L100, Pellets, Fluidized bed coating, Optimization, Central composite design

(c) 2019 The Authors. Published by Innovare Academic Sciences Pvt Ltd. This is an open access article under the CC BY license (http://creativecommons. org/licenses/by/4. 0/) DOI: http://dx.doi.org/10.22159/ajpcr.2019.v12i3.30849

\section{INTRODUCTION}

Diabetes mellitus, or simply diabetes, is a group of diseases characterized by high blood glucose levels that result from defects in the body's ability to produce and/or use insulin. It is a condition primarily defined by the level of hyperglycemia giving rise to a risk of microvascular damage (retinopathy, nephropathy, and neuropathy). It is associated with reduced life expectancy, significant morbidity due to specific diabetesrelated microvascular complications, increased risk of macrovascular complications (ischemic heart disease, stroke, and peripheral vascular disease), and diminished quality of life [1].

Several pathogenetic processes are involved in the development of diabetes. These include processes, which destroy the beta cells of the pancreas with consequent insulin deficiency, and others that result in resistance to insulin action. The abnormalities of carbohydrate, fat, and protein metabolism are due to deficient action of insulin on target tissues resulting from insensitivity or lack of insulin.

Diabetes mellitus is characteristic with symptoms such as thirst, polyuria, blurring of vision, and weight loss. Often symptoms are not severe or may be absent [2]. Diagnosis of diabetes mellitus is easily established when a patient presents the classic symptoms of hyperglycemia and has a random blood glucose value of $200 \mathrm{mg} / \mathrm{dL}$ or higher and confirmed on another occasion. Basic diagnosis of diabetes includes fasting plasma glucose (FPG) test measures blood glucose in a person who has not eaten anything for at least $8 \mathrm{~h}$. This test is used to detect diabetes and prediabetes. An oral glucose tolerance test (OGTT) measures blood glucose after a person fasts at least $8 \mathrm{~h}$ and $2 \mathrm{~h}$ after the person drinks a glucose-containing beverage [3].
FPG test is most reliable when done in the morning. Research has shown that the OGTT is more sensitive than the FPG test for diagnosing prediabetes, but it is less convenient to administer. A random plasma glucose test, also called a casual plasma glucose test, measures blood glucose without regard to when the person being tested last ate. This test along with an assessment of symptoms is used to diagnose diabetes but not prediabetes. Test results indicating that a person has diabetes should be confirmed with a second test on a different day (Twillman, 2002).

The treatment of acute diseases or chronic illness has been achieved by delivery of drugs to patients for many years. Tablets and capsules are generally formulated to release the drug immediately after oral administration to hasten systemic absorption. These are called immediate- release products. Other products like modified-release dosage forms have been developed to release the drug at a controlled rate. The purpose is generally either to avoid contact with gastric fluids (acidic environment) or to prolong drug input in the systemic circulation [4]. These drug delivery systems include tablets, parenteral, suspensions, creams, ointments, liquids, and aerosols.

Pellets are one such type of modified drug delivery system they are agglomerates of fine powders or granules of bulk drugs and excipients. They consist of small, free-flowing, spherical or semi-spherical solid units and are intended usually for oral administration. Pellets are of great interest to the pharmaceutical industry for a variety of reasons. Pelletized products not only offer flexibility in dosage form design and development but are also utilized to improve the safety and efficacy of bioactive agents. However, the single most important factor responsible for the proliferation of pelletized products is the popularity of controlled 
release technology in the delivery of drugs. Pellets containing active ingredient are administered in the form of suspensions, capsules, or disintegrating tablets [5-7] (Fig 1).

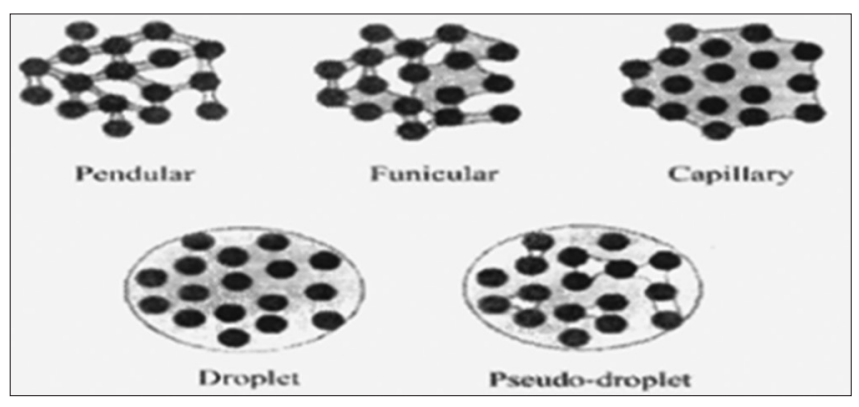

Fig. 1: Different formal spatial structures of liquid-bound agglomerates depending on liquid saturation

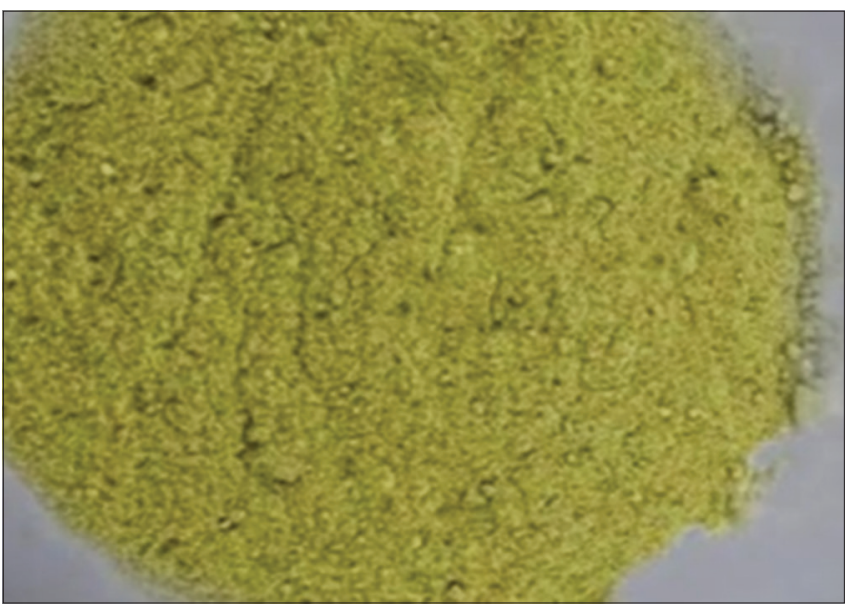

Fig. 2: Powder of Pisum sativum seeds

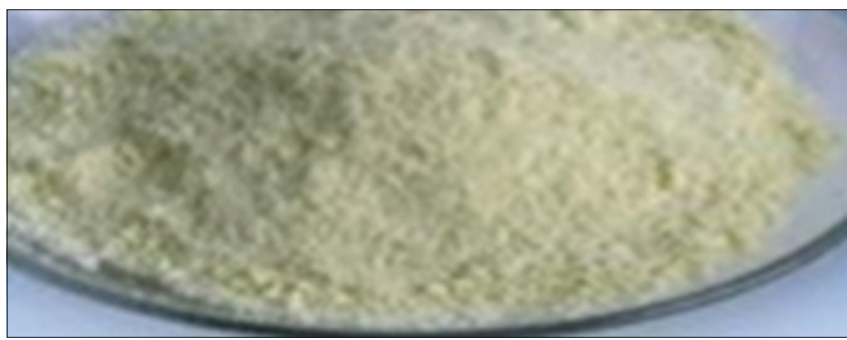

Fig. 3: Mucilage of Pisum sativum gum
Pioglitazone $\mathrm{HCl}$ was the drug chosen to be formulated as extended release pellets as it selectively stimulates nuclear peroxisome proliferators, modulates the transcription of insulin-sensitive genes involved in the control of glucose in the lipid metabolism. This drug also decreases the level of triglycerides and increases the high-density lipoproteins without changing low-density lipoproteins and the total cholesterol in the patients with disorders of lipid metabolism. It has a plasma half-life of 3-7 h.

\section{MATERIALS}

\section{Chemicals}

Pioglitazone $\mathrm{HCl}$ was obtained as a gift sample from Dr. Reddy's, Povidone, HPMC, Eudragit L-100 from Evonik Mumbai, Pisum sativum gum, acetone, methanol, isopropyl alcohol, and polyvinylpyrrolidone (PVP) K30.

\section{Equipment}

Ultraviolet-visible spectrophotometer, SL-164 double beam spectrophotometer, dissolution test apparatus, differential scanning calorimeter (DSC), Fourier transmitter-infrared spectroscopy (FT-IR), and fluidized bed processor (FBP) are used.

\section{METHODOLOGY}

\section{Isolation of gum from $P$. sativum (peas)}

About $250 \mathrm{~g}$ of $P$. sativum seeds are weighed and pulverized to a fine powder a mixer grinder. Powder of $P$. sativum was soaked in $1000 \mathrm{ml}$ of water for $24 \mathrm{~h}$ after boiled for $2 \mathrm{~h}$. The extract was filtered, and gum mucilage was isolated by separation from the marc. Ethyl alcohol was added to precipitate the gum and the gum was separated by filtration. Isolation was continued until the material was free of gum, separated gum was dried in hot air oven at temperature $40^{\circ} \mathrm{C}$, and dried gum was powdered and stored in airtight containers at room temperature (Figs. 2 and 3).

\section{Preformulation studies for pioglitazone $\mathrm{HCl}$}

This study is helpful for the investigation of physical and chemical properties of a drug substance alone and when compared with excipients. It is the first step of the rationale for the development of dosage form. Parameters such as organoleptic properties, solubility, bulk density, moisture content, angle of repose, tapped density, differential scanning calorimetry, and FT-IR analysis to check the drugexcipient compatibility in 1:1 ratio (Fig. 4 and Table 1).

\section{Formulation of extended-release pellets}

In the manufacturing of extended-release Pioglitazone $\mathrm{HCl}$ pellets, there are three stages involved in this process they include drug loading, barrier coating, and functional coating. The development of the present study was mainly based on the process of binding of the drug to inert sphere and binding of polymer on to drug-coated inert spheres. For

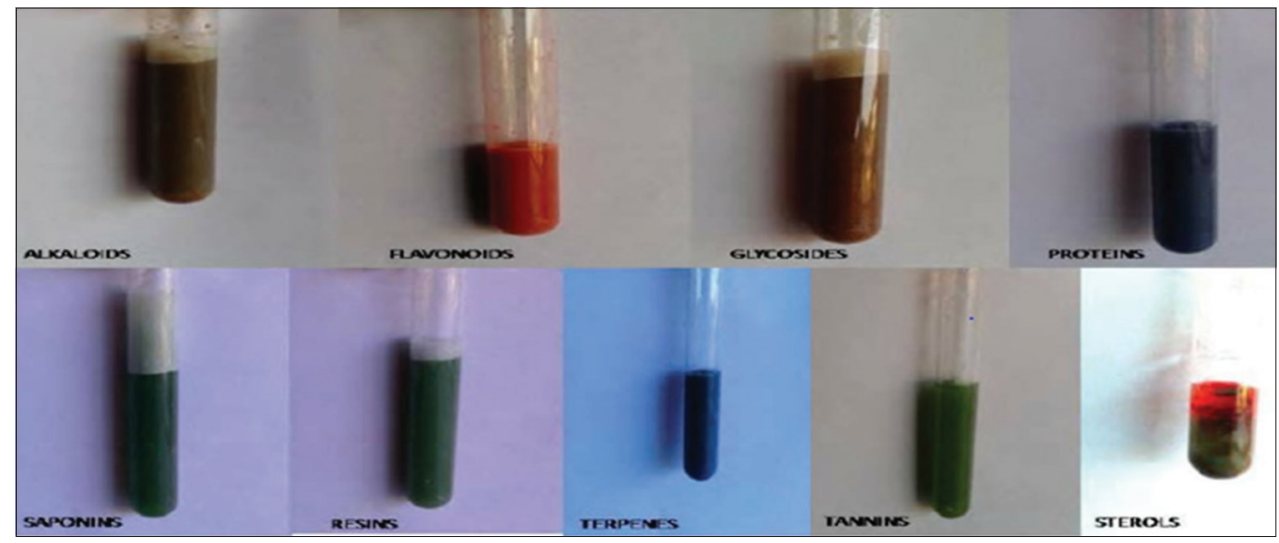

Fig. 4: Preliminary photochemical tests 
Table 1: Preliminary Phytochemical test for $P$. sativum seed gum [8,9]

\begin{tabular}{|c|c|c|}
\hline S. No & Name of test & Procedure \\
\hline 1 & Molisch test (carbohydrates) & $\begin{array}{l}\text { To the gum add } 1 \mathrm{ml} \text { of freshly prepared } \alpha \text {-naphthol solution and add conc. } \mathrm{H}_{2} \mathrm{SO}_{4} \text { from the sides of } \\
\text { the test tube under tap water. Violet ring may be formed at the junction of two liquids }\end{array}$ \\
\hline 2 & Legal's test (glycosides) & $\begin{array}{l}\text { Take extract and dissolved in pyridine and made alkaline with sodium nitroprusside solution. The } \\
\text { solution may become pink or red }\end{array}$ \\
\hline 3 & Dragendroff's test (Alkaloids) & $\begin{array}{l}\text { To the gum add Dragendroff's reagent (potassium bismuth iodide solution) to the extract. Orange-red } \\
\text { precipitate may be formed }\end{array}$ \\
\hline 4 & Salkowski test (Steroids) & $\begin{array}{l}\text { To the gum extract and dissolved in few } \mathrm{ml} \text { of chloroform and filtered. To the filtrate add an equal } \\
\text { volume of conc. } \mathrm{H}_{2} \mathrm{SO}_{4} \text {. Blue or red color may be formed }\end{array}$ \\
\hline 5 & Alkaline reagent test (Flavonoids) & $\begin{array}{l}\text { To the gum add few drops of sodium hydroxidesolution. } \\
\text { Intensive yellow color may be observed and became colorless on addition of dilute acid }\end{array}$ \\
\hline 6 & Ninhydrin test (Amino acids) & $\begin{array}{l}\text { To the small quantity of gum add } 2 \text { drops of freshly prepared } 0.2 \% \text { Ninhydrin reagent }(0.1 \% \text { solution } \\
\text { in n-butanol). Heat for few minutes, blue color may be formed }\end{array}$ \\
\hline 7 & Ruthenium test (Gums) & $\begin{array}{l}\text { Take the small quantity of dried mucilage powder and mount it on the slide with ruthenium red } \\
\text { solution and observe it under a microscope. Pink color develops }\end{array}$ \\
\hline 8 & Mucilage test (Gums) & $\begin{array}{l}\text { Take } 10 \mathrm{ml} \text { of aqueous extract of gum and add slowly to } 25 \mathrm{ml} \text { of absolute alcohol with constant } \\
\text { stirring. Filtered the precipitate and dried in air and examined for its swelling properties may indicate } \\
\text { the presence of mucilage }\end{array}$ \\
\hline
\end{tabular}

P. sativum: Pisum sativum

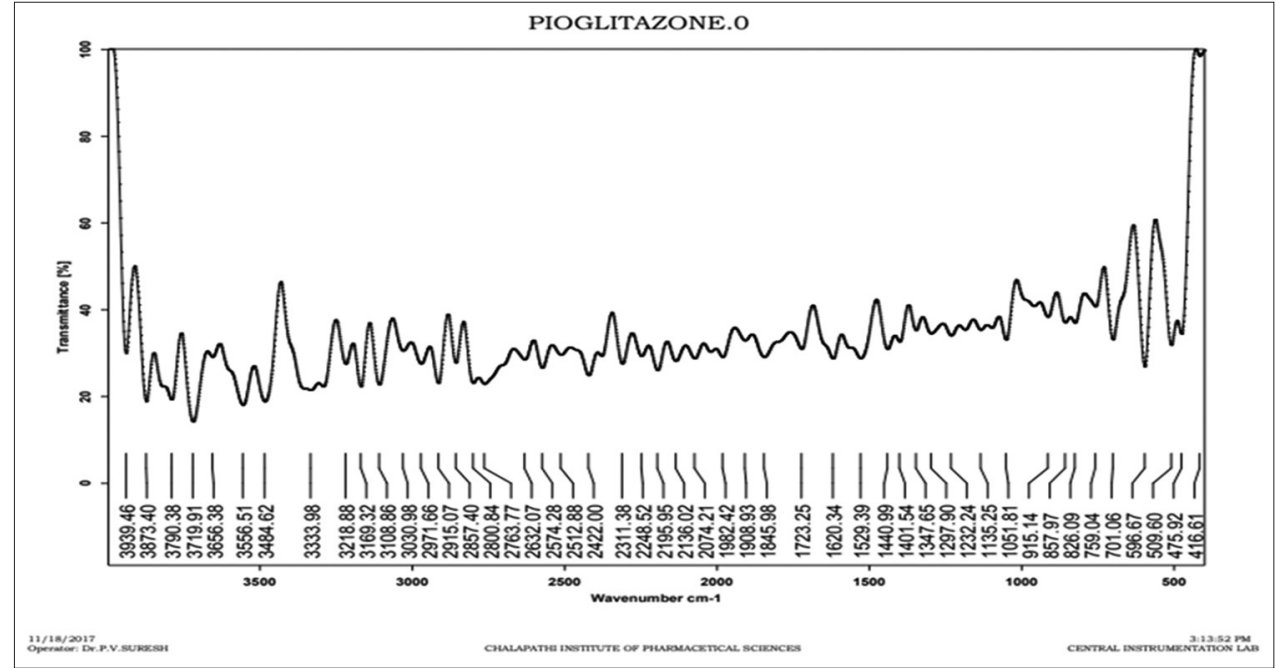

Fig. 5: Fourier transmitter-infrared spectroscopy spectrum of pure pioglitazone $\mathrm{HCl}$

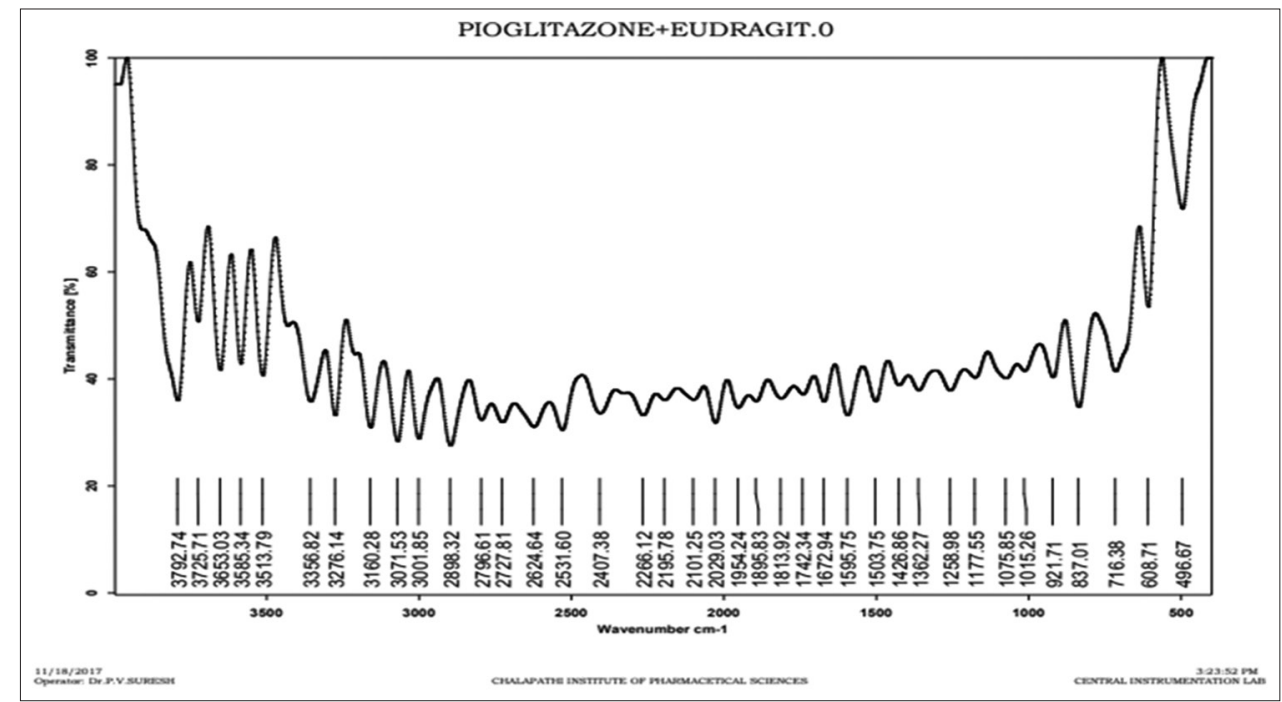

Fig. 6: Fourier transmitter-infrared spectroscopy spectrum of pioglitazone $\mathrm{HCl}+$ Eudragit-L 10

drug loading, primary coating solution was prepared using PVP K30, methanol, along with the drug on to the inert spheres. Pioglitazone $\mathrm{HCl}$ was weighed accurately and dissolved in $50 \mathrm{ml}$ of solvent (methanol) by slow addition, and continuous stirring PVP K30 was weighed and 


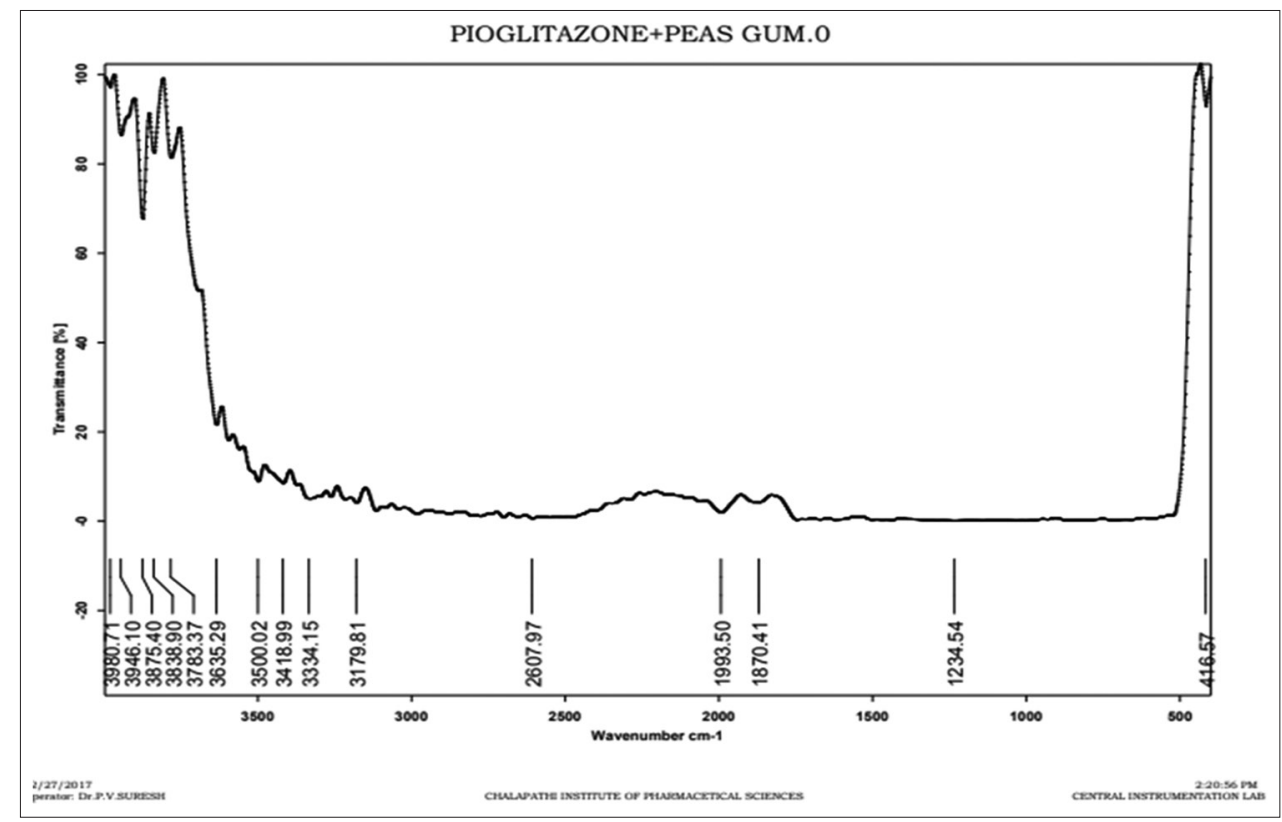

Fig. 7: Fourier transmitter-infrared spectroscopy spectra of a physical mixture of pioglitazone $\mathrm{HCl}$ and peas gum

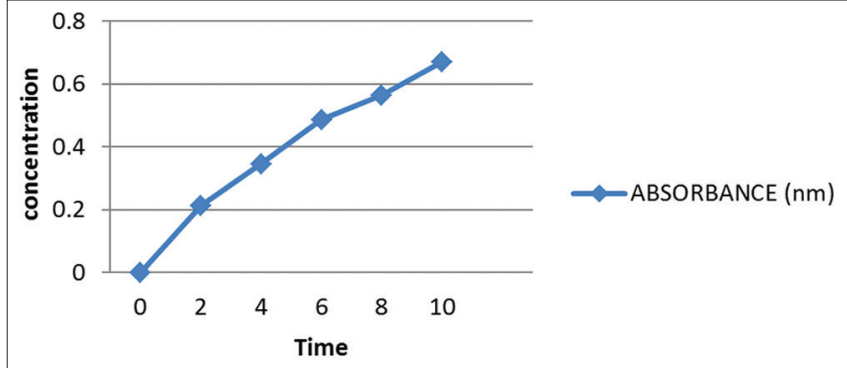

Fig. 8: Calibration curve of Pioglitazone HCl

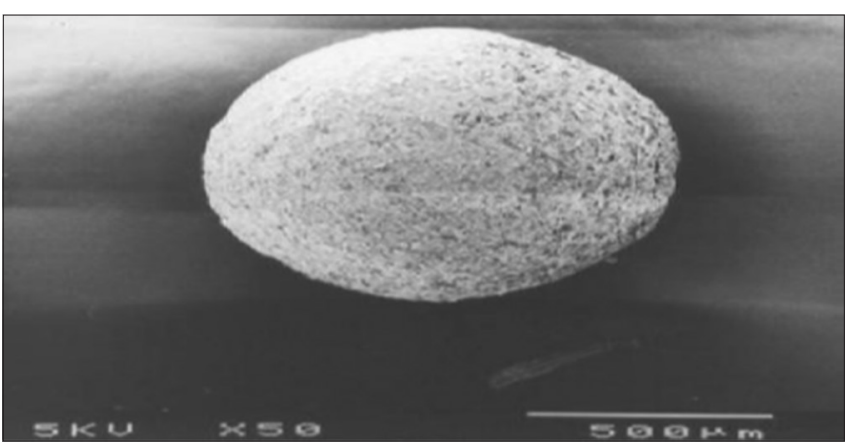

Fig. 9: Scanning electron microscopy of uncoated inert spheres

dissolved in the above solution with continuous stirring made up to $50 \mathrm{ml}$ with solvent. $50 \mathrm{~g}$ of inert spheres are weighed and kept aside pan was preheated, and the temperature of the inlet was maintained at $50-55^{\circ} \mathrm{C}$. Inert spheres were charged into the pan and operated according to the set parameters. The second step is barrier coating in this barrier coating solution was prepared using HPMC E50 LV in heated purified water. Purified water was taken and kept for heating until it reached $60^{\circ} \mathrm{C}-70^{\circ} \mathrm{C}$

The required quantity of HPMC E50 LV was taken and dissolved in purified water with continuous stirring for $30 \mathrm{~min}$ (or) until a clear solution was formed. The resulting solution was cooled to room temperature and filtered through nylon mesh, labeled and used for

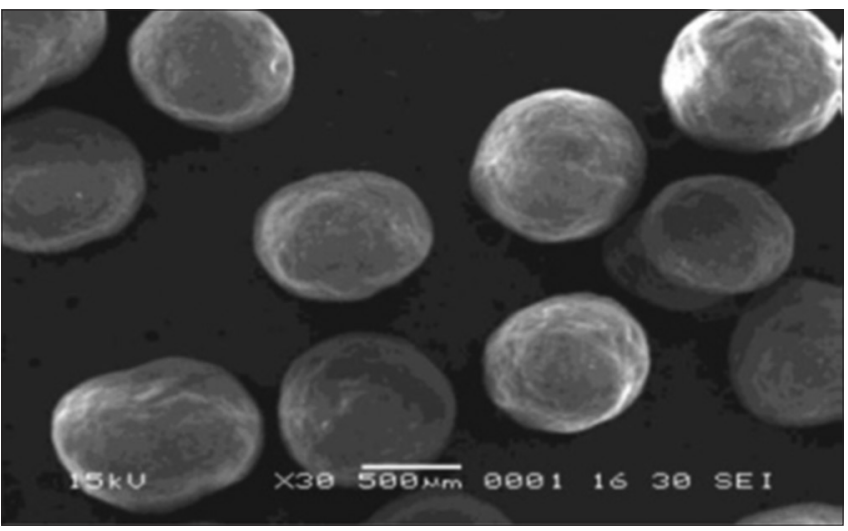

Fig. 10: Scanning electron microscopy of Pioglitazone $\mathrm{HCl}$ prepared by fluidized bed coating

Table 2: Phytochemical test of $P$. sativum gum

\begin{tabular}{|c|c|c|c|}
\hline S. No & Chemical test & $\begin{array}{l}\text { Type of chemical } \\
\text { test }\end{array}$ & $\begin{array}{l}\text { P. sativum } \\
\text { gum }\end{array}$ \\
\hline 1 & Test for carbohydrates & Molisch test & + \\
\hline 2 & Test for alkaloids & Dragendroff's test & - \\
\hline 3 & $\begin{array}{l}\text { Test for steroids and } \\
\text { sterols }\end{array}$ & Salkowski test & - \\
\hline 4 & Test for glycosides & Legal's test & - \\
\hline 5 & Test for flavonoids & Alkaline reagent test & - \\
\hline 6 & $\begin{array}{l}\text { Test for proteins and } \\
\text { amino acids }\end{array}$ & Ninhydrin test & + \\
\hline 7 & Test for gums & Mucilage test & + \\
\hline
\end{tabular}

P. sativum: Pisum sativum

coating purpose. Drug-loaded pellets were loaded into FBP, and the pellets were warmed until the product temperature of $40 \pm 2^{\circ} \mathrm{C}$ was obtained. The sub coating dispersion prepared was sprayed with the following parameters. The dispersion was kept under continuous stirring during the coating process. The coating was continued until target weight build up was obtained. The fluidization air flow was reduced to a suitable level, and the sub-coated pellets were dried at 
Table 3: Formulation of extended release pellets of pioglitazone HCL using Eudragit L-100 (EL100) as a synthetic polymer

\begin{tabular}{|c|c|c|c|c|c|c|c|c|c|}
\hline \multirow[t]{2}{*}{ S. No } & \multicolumn{2}{|c|}{ Primary coating } & \multicolumn{2}{|l|}{ Sub coating } & \multicolumn{5}{|l|}{ Functional coating } \\
\hline & Ingredient & Quantity & Ingredient & Quantity & Ingredients & E-1 & E-2 & E-3 & E-4 \\
\hline 1 & Drug & $1.5 \mathrm{~g}$ & Primary coated pellets (g) & $52 \mathrm{~g}$ & Sub-coated pellets (g) & $53 \mathrm{~g}$ & $53 \mathrm{~g}$ & $53 \mathrm{~g}$ & $53 \mathrm{~g}$ \\
\hline 2 & PVP K30 & $0.5 \%$ & HPMC E50LV & $1 \%$ & Eudragit L-100 & $1 \%$ & $2 \%$ & $3 \%$ & $4 \%$ \\
\hline 3 & Methanol & $50 \mathrm{ml}$ & Purified water & q.s & Alcohol & $50 \mathrm{ml}$ & $100 \mathrm{ml}$ & $150 \mathrm{ml}$ & $200 \mathrm{ml}$ \\
\hline \multirow[t]{2}{*}{4} & Inert spheres & $50 \mathrm{~g}$ & & & & & & & \\
\hline & Total quantity & $52 \mathrm{~g}$ & & $53 \mathrm{~g}$ & & $54 \mathrm{~g}$ & $55 \mathrm{~g}$ & $56 \mathrm{~g}$ & $58 \mathrm{~g}$ \\
\hline
\end{tabular}

PVP: Polyvinylpyrrolidone

Table 4: Formulation of extended release pellets of pioglitazone $\mathrm{HCl}$ using $P$. sativum seed gum as natural polymer

\begin{tabular}{|c|c|c|c|c|c|c|c|c|c|}
\hline \multirow[t]{2}{*}{ S. No } & \multicolumn{2}{|c|}{ Primary coating } & \multicolumn{2}{|l|}{ Sub coating } & \multicolumn{5}{|l|}{ Functional coating } \\
\hline & Ingredients & Quantity & Ingredients & Quantity & Ingredients & $\mathbf{P}-\mathbf{1}$ & P-2 & P-3 & P-4 \\
\hline 1 & Drug & $1.5 \mathrm{~g}$ & Primary coated pellets (g) & 52 & Sub-coated pellets & 53 & 53 & 53 & 53 \\
\hline 2 & PVP K30 & $0.5 \%$ & HPMC E50LV & $1 \%$ & P. sativum seed gum & $1 \%$ & $2 \%$ & $5 \%$ & $4 \%$ \\
\hline 3 & Methanol (ml) & $50 \mathrm{ml}$ & Purified water & q.s & Purified water & 50 & 100 & 250 & 200 \\
\hline \multirow[t]{2}{*}{4} & Inert spheres & $50 \mathrm{~g}$ & - & - & - & - & - & - & - \\
\hline & Total Quantity & $52 \mathrm{~g}$ & & $53 \mathrm{~g}$ & & $54 \mathrm{~g}$ & $55 \mathrm{~g}$ & $58 \mathrm{~g}$ & $57 \mathrm{~g}$ \\
\hline
\end{tabular}

PVP: Polyvinylpyrrolidone

Table 5: Micromeritic characterization of Pioglitazone $\mathrm{HCl}$ pellets

\begin{tabular}{|c|c|c|c|c|c|}
\hline S. No & Formulations & Bulk density \pm SD $(\mathrm{gm} / \mathrm{ml})$ & Tapped density \pm SD $(\mathrm{gm} / \mathrm{ml})$ & Hausners ratio $\pm S D$ & Angle of Repose $\theta \pm \mathrm{SD}^{\circ}$ \\
\hline 1 & E-1 & 0.674 & 0.706 & 1.047 & 16.6 \\
\hline 2 & E-2 & 0.676 & 0.715 & 1.054 & 21.8 \\
\hline 3 & E-3 & 0.654 & 0.695 & 1.069 & 16.34 \\
\hline 4 & E-4 & 0.653 & 0.694 & 1.068 & 16.33 \\
\hline 5 & P-1 & 0.682 & 0.708 & 1.041 & 21.8 \\
\hline 6 & P-2 & 0.678 & 0.717 & 1.049 & 16.74 \\
\hline 7 & P-3 & 0.634 & 0.675 & 1.049 & 16.12 \\
\hline
\end{tabular}

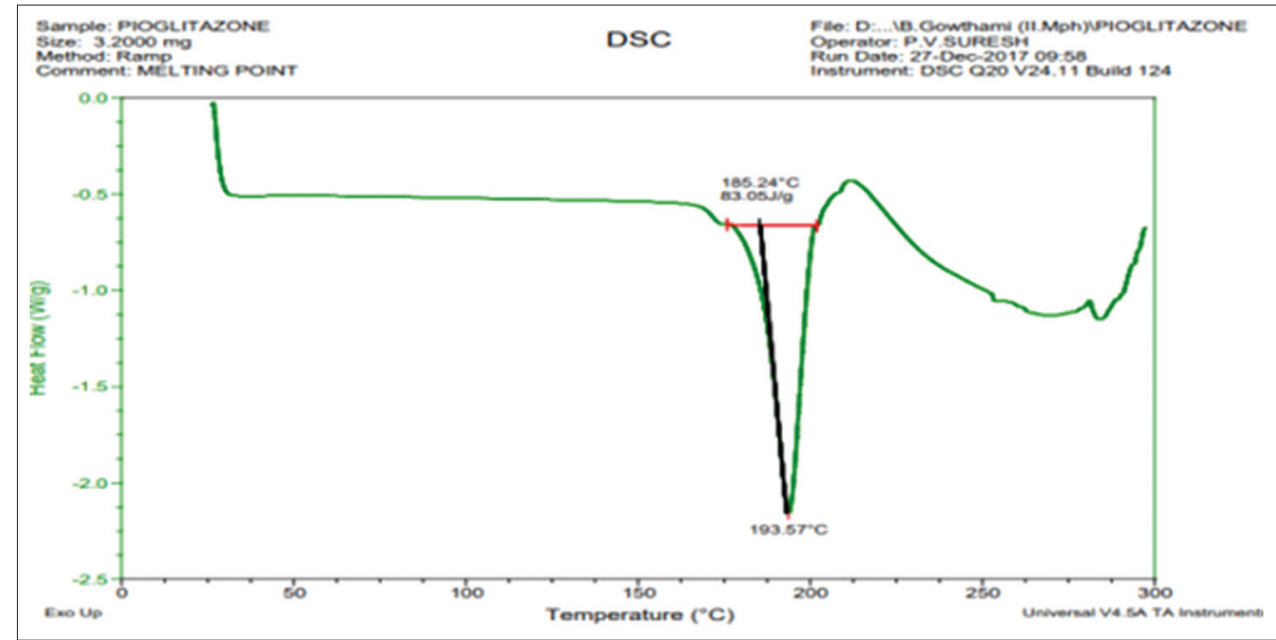

Fig. 11: Differential scanning calorimeter curve of pioglitazone $\mathrm{HCl}$

the product temperature of $33^{\circ} \mathrm{C}-35^{\circ} \mathrm{C}$ for $15-20 \mathrm{~min}$. The final step includes functional coating here using natural $P$. sativum gum and synthetic Eudragit L-100 separately coating solutions are prepared, and the coating was done, and the drug release profile are compared.

\section{Estimation of drug content}

Accurately weigh $100 \mathrm{~g}$ of formulation place it in $100 \mathrm{ml}$ volumetric flask to this add little quantity of methanol dropwise and wait for $10 \mathrm{~min}$ for complete so that pellets will be dissolved finally make up the volume with methanol. Filter the solution from the $1 \mathrm{ml}$ of the filtrate was diluted to $10 \mathrm{ml}$ with methanol. The resulted solution was analysed in UV-Spectrophotometer at $225 \mathrm{~nm}$ after suitable dilution. Content uniformity test was evaluated for the formulation by collecting samples from three different portions of the bulk, and the results were expressed, and results were reported.

In vitro - dissolution studies

The study was carried out in $900 \mathrm{ml}$ of $0.1 \mathrm{~N} \mathrm{HCl}, \mathrm{PH} 6.8$ phosphate buffer at $50 \mathrm{rpm}$. Capsules containing accurately weighed quantity of drug loaded pellets equivalent to $15 \mathrm{mg}$ to $45 \mathrm{mg}$ of Piolglitazone $\mathrm{HCl}$ were taken in USP dissolution apparatus type-I to study drug release from various formulations. The dissolution medium was kept 


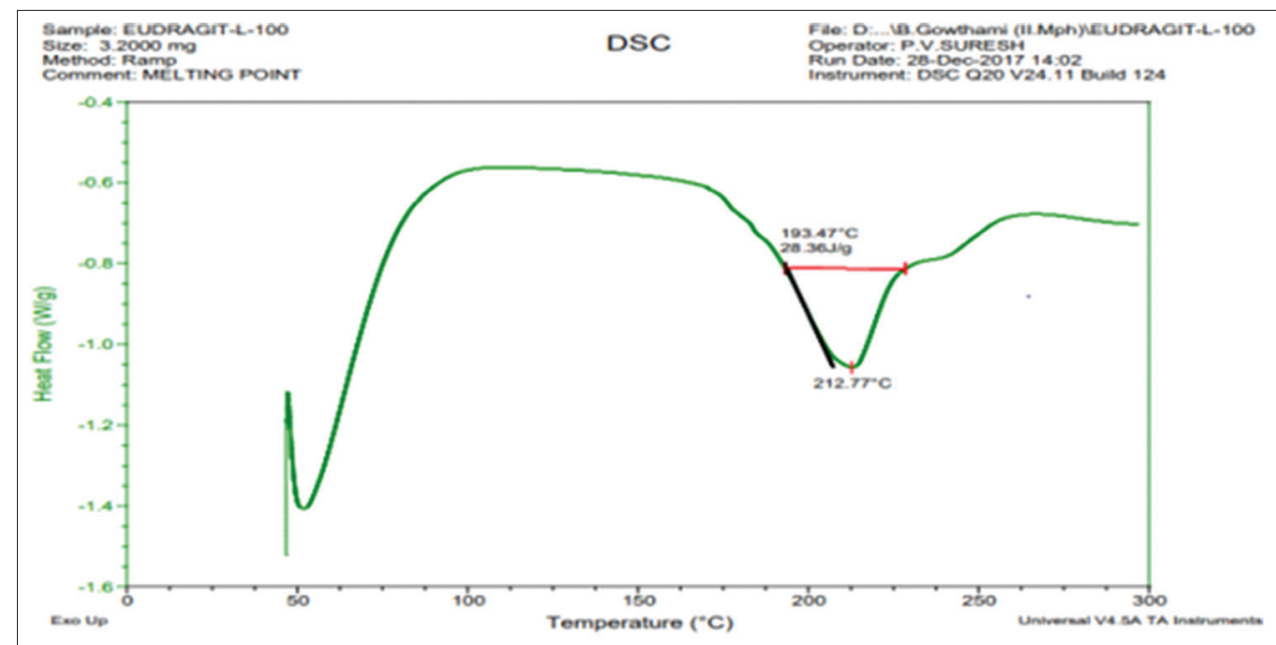

Fig. 12: Differential scanning calorimeter curve of Eudragit L-100

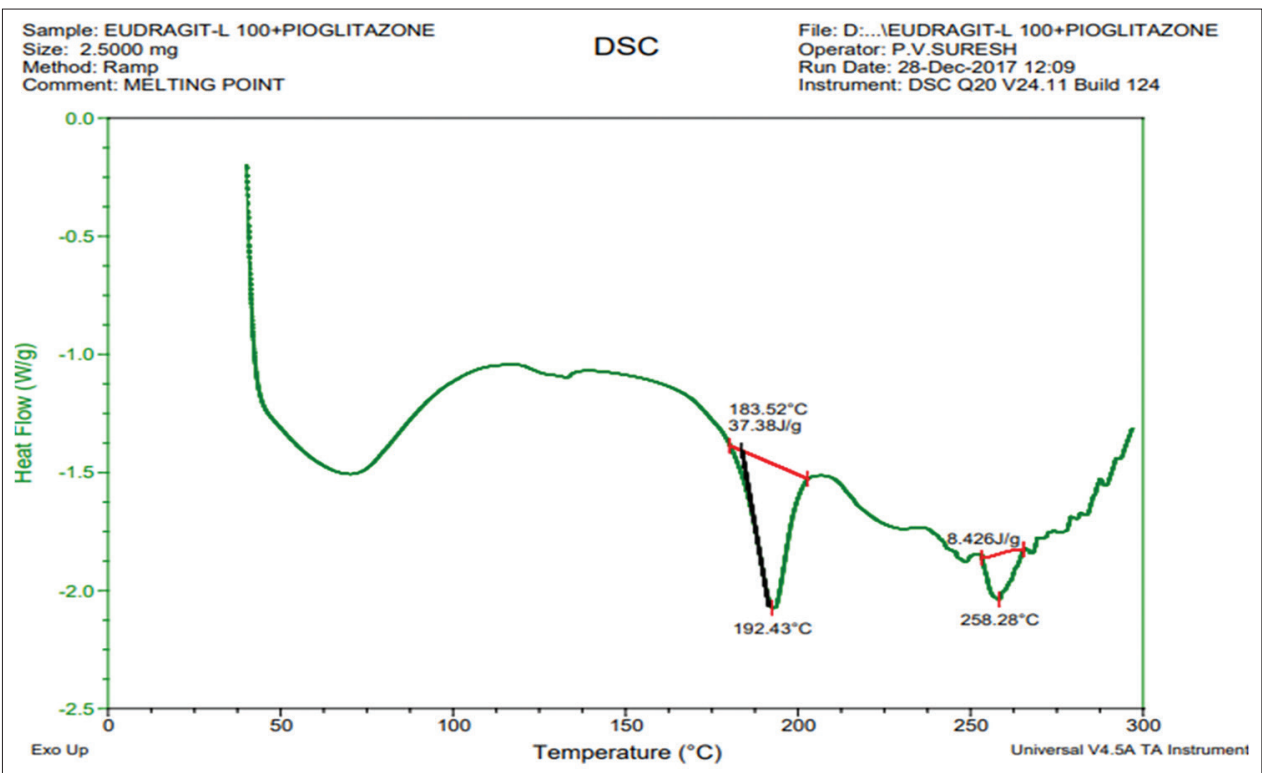

Fig. 13: Differential scanning calorimeter curve of pioglitazone $\mathrm{HCl}+$ Eudragit L-100

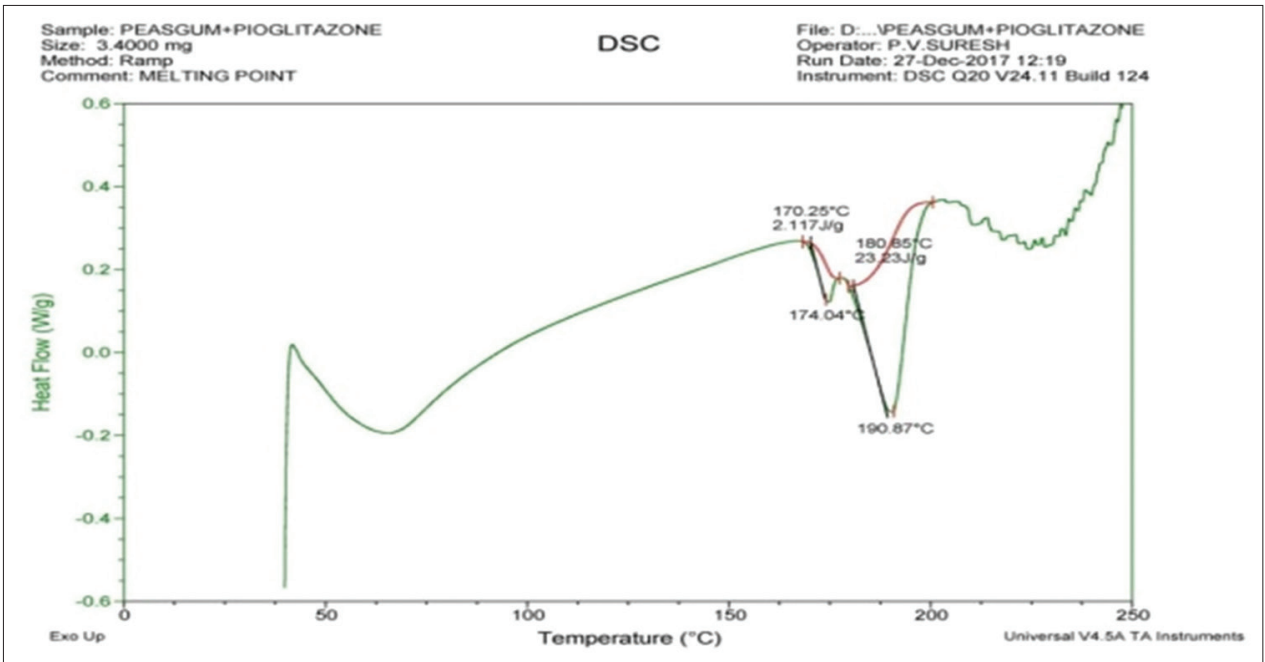

Fig. 14: Differential scanning calorimeter curve of peas gum + Pioglitazone $\mathrm{HCl}$ 


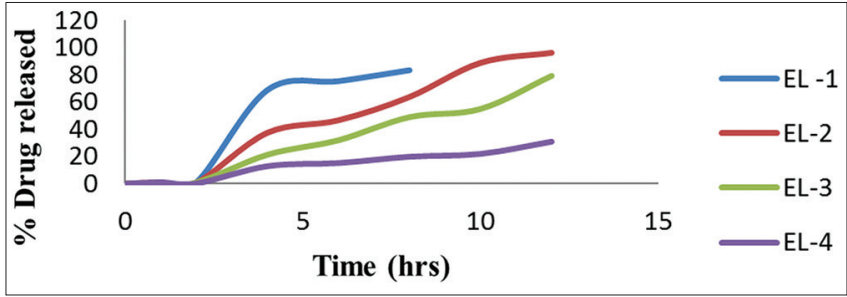

Fig. 15: Comparison of in vitro dissolution profile of formulation E-1 to E-4

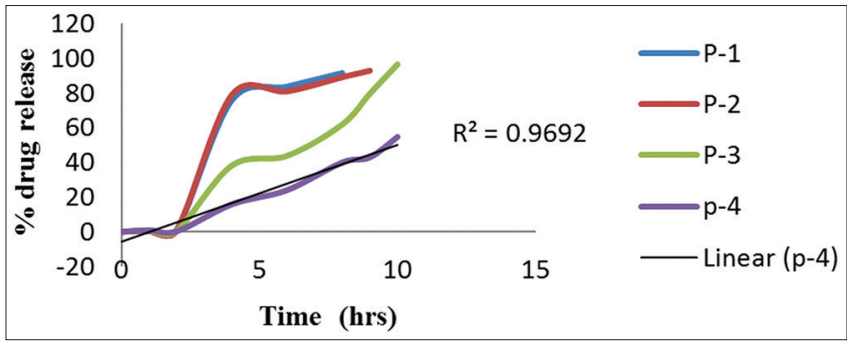

Fig. 16: Comparison of in vitro dissolution profile of formulation P -1 to P-4

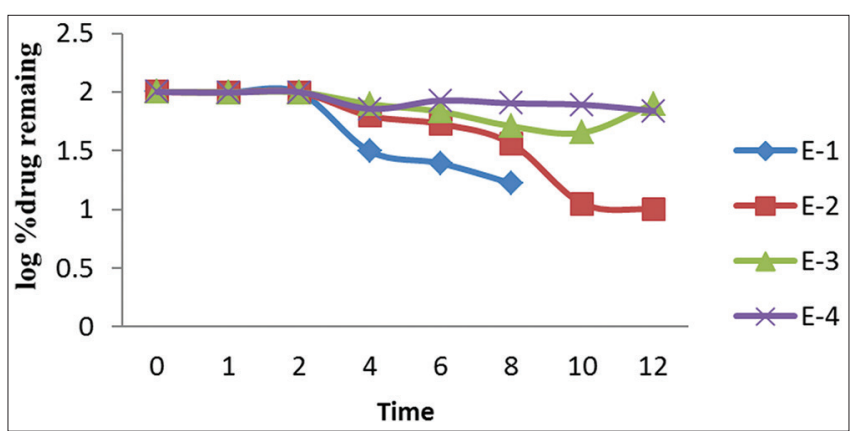

Fig. 17: First-order plot of dissolution profile of E- 1 to E-4

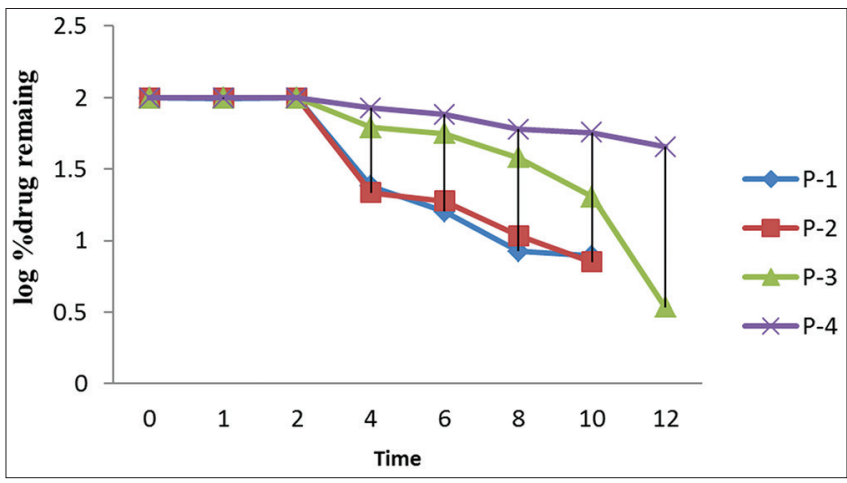

Fig. 18: First-order plot of dissolution profile of P-1 to P-4

in a thermostatically controlled water bath, maintained at $37 \pm 0.5^{\circ} \mathrm{C}$. The stirrer hood was lowered so that the lower end of the basket was $25 \mathrm{~mm}$ above the base of the beaker. At different time interval, $5 \mathrm{ml}$ of the sample was withdrawn and analyzed spectrophotometrically at $225 \mathrm{~nm}$ for drug release. At each time of interval, $5 \mathrm{ml}$ of fresh dissolution medium was replaced into dissolution flask.

Mathematical modeling and comparison of dissolution profiles Release kinetics of all the formulations was studied using Zero-order,

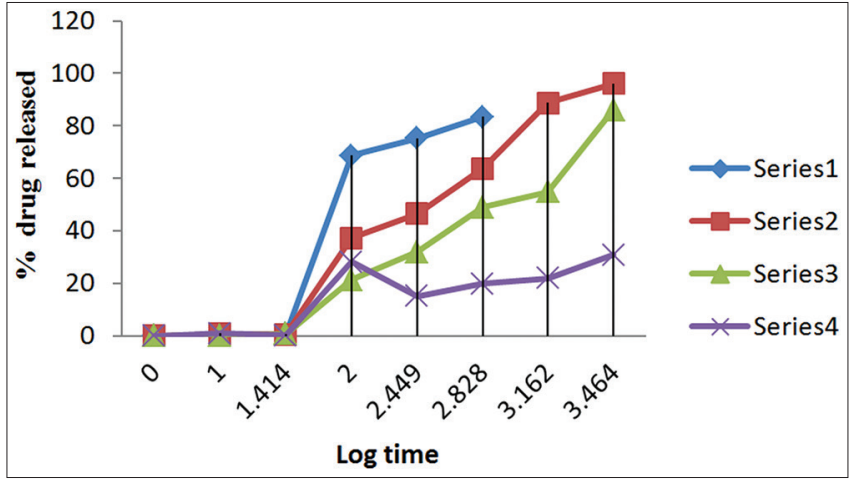

Fig. 19: Higuchi plot of dissolution profile of E-1 to E-4

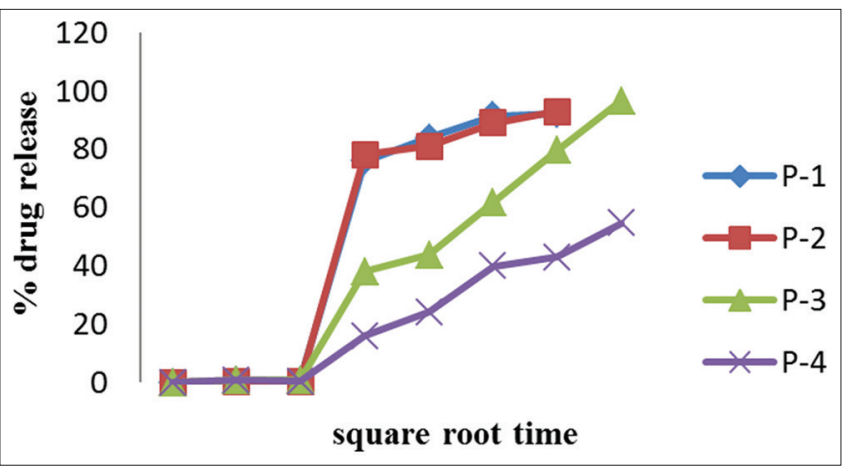

Fig. 20: Higuchi plot of dissolution profile of P-1 to P-4

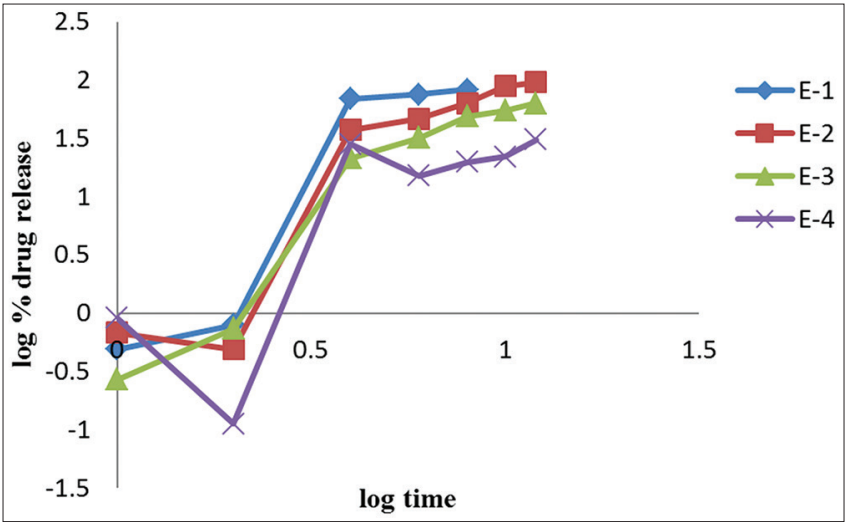

Fig. 21: Korsmeyer-Peppas plot of dissolution profiles of E-1 to E-4

Table 6: Percentage drug content

\begin{tabular}{lll}
\hline S. No & Trail & Percentage drug content (\%) \\
\hline 1 & Trail-1 & 82 \\
2 & Trail-2 & 80 \\
3 & Trail-3 & 82 \\
4 & Average & 81.3 \\
\hline
\end{tabular}

First-order, Higuchi, and Korsmeyer-Peppas mathematical models the model which best fits dissolution profile of various formulations was chosen [10-12].

\section{RESULTS AND DISCUSSION}

Physiochemical properties of $P$. sativum gum

Freshly prepared P. sativum gum is green in color with a pungent odor, 
Table 7: Drug release profile of Pioglitazone $\mathrm{HCl}$ pellets prepared by FBP

\begin{tabular}{|c|c|c|c|c|c|c|c|c|c|c|}
\hline \multirow[t]{2}{*}{ S. No } & \multirow[t]{2}{*}{ Dissolution medium } & \multirow[t]{2}{*}{ Time (h) } & \multicolumn{8}{|c|}{ Cumulative \% drug release (\%) } \\
\hline & & & E-1 & E-2 & E-3 & E-4 & P-1 & P-2 & P-3 & P-4 \\
\hline 1 & $0.1 \mathrm{~N} \mathrm{HCl}$ & 0 & 0 & 0 & 0 & 0 & 0 & 0 & 0 & 0 \\
\hline 3 & & 2 & 0.78 & 0.49 & 0.73 & 0.11 & 0.86 & 0.45 & 0.71 & 0.21 \\
\hline 4 & $\mathrm{P}_{\mathrm{H}} 6.8$ Phosphate buffer & 4 & 68.71 & 37.34 & 21.24 & 12.83 & 75.9 & 78.9 & 38.1 & 15.78 \\
\hline 5 & & 6 & 75.27 & 46.54 & 31.89 & 15.13 & 83.97 & 81 & 43.7 & 23.98 \\
\hline 6 & & 8 & 83.34 & 63.67 & 48.89 & 19.76 & 91.58 & 89.13 & 61.8 & 39.89 \\
\hline 7 & & 10 & - & 88.76 & 54.85 & 21.85 & 92.14 & 92.9 & 79.81 & 42.89 \\
\hline 8 & & 12 & - & 96.13 & 79.18 & 30.86 & - & - & 96.57 & 54.7 \\
\hline
\end{tabular}

Marketed Pioglitazone tablets shown a release profile up to 3-6 h, FBP: Fluidized bed processor

Table 8: Dissolution kinetics of Pioglitazone HCL pellets formulated with natural and synthetic polymers

\begin{tabular}{lllll}
\hline \multirow{2}{*}{ Formulation code } & \multicolumn{4}{l}{ Correlation coefficient $\left(\mathbf{R}^{2}\right)$} \\
\cline { 2 - 5 } & Zero-order & First-order & Higuchi & Peppas \\
\hline E-1 & 0.864 & 0.873 & 0.832 & 0.875 \\
E-2 & 0.973 & 0.866 & 0.946 & 0.864 \\
E-3 & 0.968 & 0.538 & 0.924 & 0.931 \\
E-4 & 0.957 & 0.689 & 0.703 & 0.658 \\
PS-1 & 0.862 & 0.906 & 0.825 & 0.568 \\
PS-2 & 0.844 & 0.908 & 0.820 & 0.836 \\
PS-3 & 0.960 & 0.763 & 0.949 & 0.140 \\
PS-4 & 0.969 & 0.925 & 0.943 & 0.788 \\
\hline
\end{tabular}

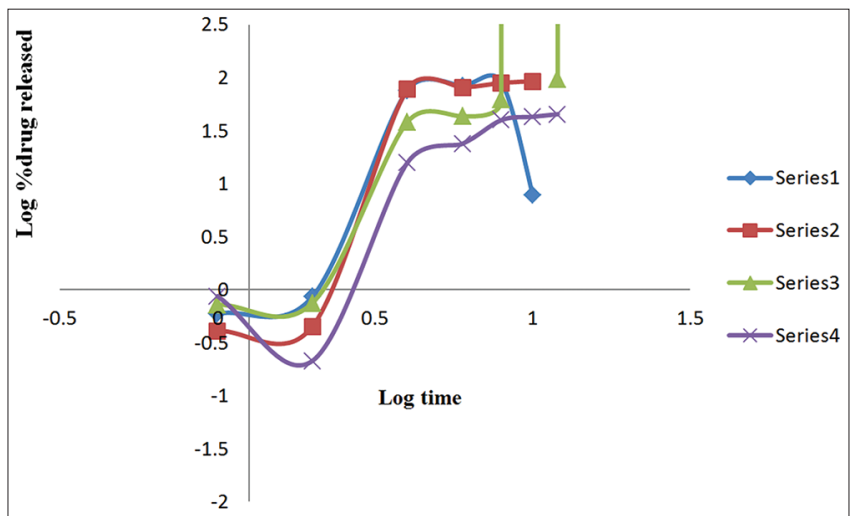

Fig. 22: Korsmeyer-Peppas plot of dissolution profile of P-1 to P-4

found to soluble in water and insoluble in organic solvents such as ethanol, alcohol, and acetone, and $\mathrm{pH}$ of $2 \% \mathrm{w} / \mathrm{v}$ aqueous mucilage was 7.22-7.30. The initially apparent viscosity of $2 \% \mathrm{w} / \mathrm{v}$ of peas seed gum was less and almost constant after $1 \mathrm{~h}$ of soaking time and further increase the viscosity after $3 \mathrm{~h}$. The apparent viscosity of $2 \%$ $\mathrm{w} / \mathrm{v}$ of gum dispersion using spindle II (DV-II+ pro viscometer) and the viscosity is measured at different rpm, i.e., from 10 to 100 . Gum dispersion followed non-Newtonian flow because it has different viscosity at a different shear rate (Table 2).

\section{Physicochemical characterization of drug}

Physicochemical parameters of the obtained sample of the drug were analyzed color was white with a bitter taste in amorphous state soluble in methanol with a melting point $194^{\circ} \mathrm{C}$.

FR-IR studies for the pure drug, drug along with eudragit L-100 and seed gum

Pioglitazone $\mathrm{HCl}$ and peas gum show no uncountable peak which confirms the absence of chemical interaction between the drug and polymer. The IR spectra of the drug and polymer, drug-polymer mixture are shown in Figs. 5-7 and Tables 3 and 4. On comparison of a physical mixture of Pioglitazone $\mathrm{HCl}$ and Eudragit L-100, Pioglitazone $\mathrm{HCl}$ and $P$. sativum gum by superimposing IR spectra there is no interaction between drug and polymer.

Calibration curve of pioglitazone $\mathrm{HCl}$

A calibration curve was constructed for Pioglitazone $\mathrm{HCl}$ in methanol at $225 \mathrm{~nm}$ using ultraviolet-visible spectrophotometer (Fig. 8).

Evaluation of the micromeritic properties of pioglitazone $\mathrm{HCl}$ pellets

The flow properties of pellets were evaluated for bulk density, tapped density angle of repose, Carr's index, and Haussner's ratio. The limits were given in Table 5 .

\section{Drug content}

The content uniformity test was evaluated for the formulation by collecting samples from three different portions of the bulk, and the results were expressed. (Table 6) The results were reported as:

\section{Characterization of pellets}

Based on the dissolution studies performed on all the batches of pellets, some of the optimized formulations were selected and further investigated for DSC and scanning electron microscopy (SEM) studies.

\section{Shape and surface roughness}

The pellets formulation was examined by SEM for the surface characteristic, SEM photographs of pellets were shown in Figs. 9 and 10 . The pellets prepared by fluid bed coating have smooth surface with minimal pores indicated the uniform coating of pellets.

\section{DSC studies}

About $3.052 \mathrm{mg}$ of sample was weighed in a standard open aluminum pan, and scanned from 30 to $300^{\circ} \mathrm{C}$, at a heating rate of $10^{\circ} \mathrm{C}$ min while being purged with dry nitrogen (Figs. 11-22 and Tables 7 and 8). Results are given as thermographs.

\section{CONCLUSION}

In the present investigation, Pioglitazone $\mathrm{HCl}$ was taken as a model drug in the sustained drug delivery system for extending drug release for a prolonged period of time as pellets. Multiparticulate drug delivery system is developed by employing FBP, as multiparticulates are more advantageous over single unit systems due to their small size. Extended-release pellets of Pioglitazone HCL were formulated and evaluated, Eudragit L-100 is used as a synthetic polymer to retard the release of the drug, and P. sativum seed gum is used as a natural polymer in the development of extended-release formulations. The best formulations were selected based on in vitro dissolution studies. Based on preformulation studies, it was proved that there are no compatibility issues regarding the excipients with the drug. SEM analysis was performed for the pellets prepared by fluid bed coating. The pellets prepared by FBP were having a smooth surface with minimal pores which indicate uniform coating of pellets. Drug content and content 
uniformity were found to be good and gave reproducible results. It was found that among the various batches of the formulations E- 2 and P-3 prepared by fluid bed coating were found to release the drug over an extended period of time, i.e., up to $12 \mathrm{~h}$. Release kinetics revealed that all the formulations were following zero-order drug release and are suitable for prolonging the antidiabetic activity. The current antidiabetic medications available in the market containing Pioglitazone $\mathrm{HCl}$ do not possess sustained release formulations. Furthermore, the use of natural polymers must be adopted to reduce toxic solvents utility in fluidized bed coating systems and fasten the bioavailability of the medicament. Hence, the present investigation could be apt enough to meet the requirements of polymer availability on a large scale.

\section{AUTHOR'S CONTRIBUTIONS}

Authors are extremely thankful to Chalapathi Institute of Pharmaceutical Sciences for providing necessary research facilities for successful completion of their research.

B. Gowthami has worked on natural gum extracts and its isolation procedure.

Santhi Priya Nagam has contributed her expertise on pellets preparation, coating parameters, formulation of coating solutions and their characterization also in the interpretation of kinetics and statistical analysis.

Prof. Rama rao Nadendla was working guide for this research work, has guided the spectral analysis, biochemical interpretations, and pharmacokinetic studies, and has also authored many books on medicinal and natural chemistry.

Nihitha. S contributed on corresponding and compilation of literature, communication of research work to the reputed and esteemed journal.

\section{ACKNOWLEDGMENT}

I extend my thankfulness to my guide, the Principal and Chalapathi Institute of Pharmaceutical Sciences for all equipment, guidance the support and successful completion of the project work and also thank
Dr. Reddy's, Hyderabad, for Pioglitazone $\mathrm{HCl}$ and Evonik, Mumbai, for Eudragit gift samples.

\section{CONFLICTS OF INTEREST}

The authors declare that there are no conflicts of interests regarding the publication of this paper.

\section{REFERENCES}

1. Holt RI, Cockram C, Flyvbjerg A, Goldstein BJ. Textbook of Diabetes. $4^{\text {th }}$ ed. UK: Wiley-Back Well; 2010

2. Ramesh C, Rani AP. In vivo and in vitro evaluation of Tephrosia calophylla for anti-diabetic properties. Int $\mathrm{J}$ Pharm Pharm Sci 2018;10:77-84.

3. Aalto AM, Uutela A, Aro AR. Health related quality of life among insulin-dependent diabetics: Disease-related and psychosocial correlates. Patient Educ Couns 1997;30(3):215-25.

4. Patel SA, Patel NG, Joshi AB. Multiple unit pellet system (MUPS) based fast disintegrating delayed-release tablets for pantoprazole delivery. Int J Pharm Pharm Sci 2018;10:138-44.

5. Jain K. Gastro Retentive Drug Delivery: Progress in Controlled and Novel Drug Delivery System. $1^{\text {st }}$ ed. New Delhi: CBS Publisher and Distributer; 2004. p. 82-90

6. Asian Edition. The United State Pharmacopeia. New York: Asian Edition; 2000. p. 2059.

7. Grass GM., Robinson JR, Dekker M. In: Banker GS, Rhodes CT, editors. Modern Pharmaceutics. New York: Informa Healthcare USA Inc.; 1996. p. 635

8. Ali M. Textbook of Pharmacognosy. $2^{\text {nd }}$ ed. New Delhi: CBS Publishers and Distributors; 2012. p. 71-90.

9. Kokate C, Purohit A, Gokhle S. Pharmacognosy. $42^{\text {nd }}$ ed. Pune: Nirali Prakashan; 2008

10. Begum R, Aleemudin M, Gautam T. Effect of natural gums on oral sustained release matrix tablets of chloroxone. Int Res J Pharm 2012;3:426-7.

11. Rao NR, Yadav A. Formultion and evaluation of zero order release glipizide bilayer matrix tablet using natural and synthetic polymers. Int J Curr Pharm Res 2010;2:34-42.

12. Kumar AA. Formulation and evaluation of sustained release valsatran matrix tablets by using natural polymers. Int J Pharm Chem Biol Sci 2012;2:146-50. 